\title{
Mineralization of pyrene induced by interaction between Ochrobactrum sp. PW and ryegrass in spiked soil
}

\author{
Tuo Liu ${ }^{\mathrm{a}, 1}$, Lianshuang Wei ${ }^{\mathrm{a}, 1}$, Min Qiao ${ }^{\mathrm{b}}$, Dexun Zou ${ }^{\mathrm{a}}$, Xiaojin Yang ${ }^{\mathrm{a}}$, Aijun Lin ${ }^{\mathrm{a}, \mathrm{c}, *}$ \\ a Department of Environmental Science and Engineering, Beijing University of Chemical Technology, Beijing 100029, PR China \\ b Department of Soil Environmental Sciences, Research Center for Eco-Environmental Sciences, Chinese Academy of Sciences, Beijing 100085, PR China \\ ${ }^{\mathrm{c}}$ Beijing City Environmental Pollution Control and Resource Reuse Engineering Research Center, Beijing University of Chemical Technology, Beijing 100029, \\ PR China
}

\section{A R T I C L E I N F O}

\section{Article history:}

Received 20 April 2016

Received in revised form

22 July 2016

Accepted 22 July 2016

Available online 30 July 2016

\section{Keywords:}

Degradation bacteria

PW

Ryegrass

Pyrene

Combined remediation

\begin{abstract}
A B S T R A C T
This study was conducted to investigate the capability of pyrene-degrading bacterium Ochrobactrum sp. PW and ryegrass (Lolium multiflorum) grown alone and in combination on the degradation of pyrene in soil. After 60 days of ryegrass growth, plant biomass, pyrene-degrading microbial mass, soil enzyme activity (catalase activity and polyphenol oxidase activity) and residual concentration of pyrene in soils were determined. Higher dissipation rates were observed in PW inoculation treatments: ryegrass + PW rhizosphere soil (RP-r) and ryegrass + PW non-rhizosphere soil (RP-nr), than planting of ryegrass alone, rhizosphere $(\mathrm{R}-\mathrm{r})$ or non-rhizosphere $(\mathrm{R}-\mathrm{nr})$. The inoculation with PW significantly $(\mathrm{p}<0.05)$ increased the dry weight of ryegrass root and shoot, nearly 2.8 and 3.3 times higher than ryegrass treatment. The pyrene-degrading microbial mass indicated that a much larger mass of bacteria, actinobacteria were present in RP treatment. The catalase activity in all different treatments were significantly $(p<0.05)$ higher than in with treatment R-nr, and the polyphenol oxidase activity was also significantly $(p<0.05)$ increased by inoculation with PW, leading to enhanced mineralization of pyrene from soil. Our results suggest that adding of PAHs-degrading bacteria to soil can enhance remediation of PAHs contaminated soil, while improving plant growth.
\end{abstract}

(c) 2016 Elsevier Inc. All rights reserved.

\section{Introduction}

Polycyclic aromatic hydrocarbons (PAHs) are one class of are a group of persistent organic pollutants (POPs) that have accumulated ubiquitously in the environment (Zhang et al., 2015). They may present in high concentrations in soil because of naturally occurring deposits, incomplete combustion of fossil fuels and biomasses, development of traffic and transportation industry and so on (Samanta et al., 2002; Wilcke, 2007). These pollutants are toxic, possess carcinogenic, mutagenic and teratogenic properties and have potential to accumulation in organisms, PAHs pose a significant risk to environmental and human health (Beg et al., 2003; Moscoso et al., 2012; Samanta et al., 2002). The contamination of soil environment by PAHs is paid widely attention in the whole world (Oleszczuk, 2009). Thus, the deleterious properties of PAHs have made their remediation a critical need.

Currently, three major technologies are available to deal with

\footnotetext{
* Corresponding author at: Department of Environmental Science and Engineering, Beijing University of Chemical Technology, Beijing 100029, PR China.

E-mail address: environbiol@mail.buct.edu.cn (A. Lin).

${ }^{1}$ These authors contributed equally to this work and should be considered cofirst authors.
}

the PAHs contaminated soil: chemical, physical and bioremediation. Because of the lower cost, thorough mineralization, less secondary pollution, bioremediation has been suggested to be an efficient and economical technology to clean up contaminated soils by PAHs (Margesin and Schinner, 1997; Sayara et al., 2011). As an environment friendly approach, bioremediation includes phytoremediation, microbial remediation and microbe-plants combined remediation. The growth of plants may be restrained when the concentration of contaminants was at a very high level in soil, so the activities of microbe in the rhizosphere also were reduced inducing less PAHs mineralization. On the other hand, the efficient PAHs degrading bacteria can endure the high concentration of PAHs due to the production of PAHs degrading enzymes and surfactant (Husain, 2008), but it should grow in a strict condition to achieve the mineralization of PAHs. So when added to the soil the high-efficient PAHs degrading bacteria could not compete with the indigenous flora limiting the growth of the strains. Thus, the bioavailability of PAHs in soil, plant uptake and transformation capacity and the biological diversity in soil would greatly influence the efficiency of PAHs remediation.

There are two principal factors in PAHs degradation Plant-microorganism combined bioremediation: The reactions of PAHs degradation by microorganisms are usually ascribed to their 
oxidative enzymes (Baldrian and Wiesche, 2000), which can have effects on K-region and bay-region of the PAHs and ultimately render them non-toxic (Kim et al., 2005). On the other hand, degradation of PAHs by microorganisms has been shown stimulated by root exudates and fine root turnover through providing readily available organic matters that would elevate microbial population (Miya and Firestone, 2001) and cometabolites that induce the cometabolism of PAHs (Ruuhola, 2000). Ryegrass is widely used in the phytoremediation of PAH-contaminated sites owing to its fibrous root system and large specific root surface area (Kang et al., 2010).

In the present research, the degradation mechanisms in soil and interactions among pyrene-degrading bacteria and plant as well as their effects on PAH dissipation are still poorly understood. The objectives of this experiment were therefore to investigate: (1) the effect of pyrene-degrading bacterium and ryegrass, and their interaction on PAHs mineralization and (2) the principal factor in PAHs dissipation by pyrene-degrading bacteria and ryegrass. Some possible mechanisms related to enhanced bioremediation including number of bacteria, actinobacteria and fungi as well as soil oxidoreductase activity and its relationships with plant biomass and pyrene dissipation.

\section{Materials and methods}

\subsection{Chemicals and media}

Pyrene with a purity of $99.9 \%$ was purchased from Sigma-Aldrich Co. Ltd. All the other solvents and chemicals used in this study were of reagent grade or better. Mineral salt medium (MSM) contained the following chemicals (per liter): $\mathrm{K}_{2} \mathrm{HPO}_{4}, 4 \mathrm{~g}$; $\mathrm{Na}_{2} \mathrm{HPO}_{4}, 4 \mathrm{~g} ; \quad\left(\mathrm{NH}_{4}\right) \mathrm{SO}_{4}, 2 \mathrm{~g} ; \mathrm{MgSO}_{4}, 0.2 \mathrm{~g} ; \mathrm{CaCl}_{2}, 1 \mathrm{mg}$; $\mathrm{FeSO}_{4} \cdot 7 \mathrm{H}_{2} \mathrm{O}, 1 \mathrm{mg}$; pH 7.0-7.2. Peptone beef medium contained: beef extract, $1.5 \mathrm{~g}$; peptone, $2.5 \mathrm{~g}$; agar, $2.5 \mathrm{~g}$; distilled water, $500 \mathrm{ml}$.

\subsection{Isolation of pyrene-degrading bacteria and phylogenetic analysis}

Enrichment was carried out by adding $5 \mathrm{~g}$ PAHs contaminated soil of coking plant (Beijing, China) into $100 \mathrm{ml}$ MSM medium, and incubated with shaking at $30^{\circ} \mathrm{C}, 150 \mathrm{r} / \mathrm{min}$ for 5 days in the dark. Then $10 \mathrm{ml}$ of supernatant was transferred into a new MSM medium with pyrene as sole carbon source, after incubation for 5 days, the same amount of supernatant was transferred several times with an increasing concentration of pyrene until it was $5 \mathrm{mmol} \mathrm{l}^{-1}$. At the end of enrichment, pyrene-degrading bacterium was separated by plate streaking in peptone beef medium repeatedly.

16S rDNA was amplified from genomic DNA of isolated bacteria using the primer pair 8F: 5'-AGAGTTTGATCCTGGCTCAG-3' and 1492R: 5'-GGTTACCTTGTTACGACTT-3'. The PCR conditions were 35 cycles of $94{ }^{\circ} \mathrm{C}$ for $4 \mathrm{~min}, 63^{\circ} \mathrm{C}$ for $1 \mathrm{~min}, 72{ }^{\circ} \mathrm{C}$ for $1 \mathrm{~min}$, followed by one cycle of $72{ }^{\circ} \mathrm{C}$ for $7 \mathrm{~min}$. The PCR products were purified and sent to be sequenced. The sequences were submitted to the GenBank database to align with published sequences using NCBI BLASTN. The software MEGA (version 4.0) was used to construct phylogenetic trees.

\subsection{Soil and plant}

The soil $(0-25 \mathrm{~cm})$ samples used in the experiment were obtained from Tiantongyuan of Beijing, China. This soil had been classified as a typical brown soil, and had no background concentration of exposure to PAHs and other contaminants. The soil was air-dried and sieved to $2 \mathrm{~mm}$ mesh. The soil $\mathrm{pH}$ was 8.4 , organic matter content 3.5\% and the cation exchange capacity (CEC) $15.9 \mathrm{cmol} \mathrm{kg}^{-1}$.

The Perennial ryegrass seeds were disinfected in $10 \% \mathrm{H}_{2} \mathrm{O}_{2}$ (w/ w) solution for $10 \mathrm{~min}$, followed by thorough washing with distilled water. The seeds were then germinated in dark at $25^{\circ} \mathrm{C}$. Seedlings with uniform appearance were selected for the experiment use 3 days later.

\subsection{Experimental design}

Soil was spiked with a high concentration of pyrene in acetone ( $10 \%$ of the total quantity of soil to be used was spiked first). When acetone evaporated off overnight, the resulting PAH-spiked soil sample was mixed with the residual PAH-free soil and passed through a $2 \mathrm{~mm}$ sieve to achieve homogeneity. The soil was then packed into plastic bags, and placed in the dark at room temperature for 2 weeks. After aging, partial of spiked soil was inoculated with PW (name of the pyrene-degrading bacteria obtained in 2.2) with a population of $3.5 \times 10^{9} \mathrm{CFU} \mathrm{g}^{-1}$ (CFU: ColonyForming Units) soil, then packed the soils into different root boxes as required (12 cm in length, width and height, Fig. 1).

Each root box contained $1 \mathrm{~kg}$ of spiked soil, and distilled water was added to adjust the moisture of soil to $60 \%$ of field water capacity and maintained for 3 days. The experiment had two treatment groups: (1) planting of ryegrass (R); (2) planting of ryegrass plus $\mathrm{PW}$ inoculation (RP). Four replicates of each group were prepared. Under each treatment the root box was used to separate the soil into two parts: the rhizosphere soil (r) and nonrhizosphere soil (nr). The ryegrass seedlings were transplanted in the middle of the root box (12 seedlings each box). The seedlings transplantation was considered as the start of the experiment. The soil moisture content was adjusted once a day to $60 \%$ of field water capacity with distilled water. All the root boxes were arranged randomly in an incubator, with temperature control $\left(20-25^{\circ} \mathrm{C}\right)$, and with illumination (with a light intensity of $250 \mu \mathrm{mol} \mathrm{m}^{-2} \mathrm{~s}^{-1}$, under a $14 / 10 \mathrm{~h}-$ light/dark cycle). After 60 days growing, the shoot of ryegrass were collected firstly, then the root boxes were disconnected, the rhizosphere soils, non-rhizosphere soils and the root of ryegrass were collected separately into plastic bags, and waited for the following analysis.

\subsection{Analytical methods}

\subsubsection{Plant biomass}

The harvested plant shoots and roots were fully washed in tap water followed by distilled water to remove residual soil particle on the surfaces, then freeze-dried for $48 \mathrm{~h}$ and weighed.

\subsubsection{Number of pyrene-degrading microbe}

To enumerate the viable pyrene-degrading microbial population, aqueous extracts of $10 \mathrm{~g}$ soil samples were added to $90 \mathrm{ml}$ sterilized water, then serially diluted and spread on different nutrient agars for bacteria, actinobacteria and fungi, which contained $100 \mathrm{mg} \mathrm{l}^{-1}$ pyrene. Three replicates were prepared of each dilution. Plates were incubated for $3-5$ days at $28^{\circ} \mathrm{C}$. The number was expressed as colony-forming units (CFU) $\mathrm{g}^{-1}$ soil.

\subsubsection{Soil enzyme activity analysis}

Catalase (E.C. 1.11.1.6) activity in soils was determined by the method of Temple and Johnson (1964) and Lee et al. (2007) and with some modifications, it was measured by adding hydrogen peroxide and determining the disappearance rate of $\mathrm{H}_{2} \mathrm{O}_{2}$ over time. Four grams of fresh soil was mixed with $40 \mathrm{ml}$ distilled water and $5 \mathrm{ml} 0.3 \% \mathrm{H}_{2} \mathrm{O}_{2}$, shaken for $20 \mathrm{~min}$ at $150 \mathrm{r} / \mathrm{min}$. After incubation, $5 \mathrm{ml}$ of $1.5 \mathrm{M} \mathrm{H}_{2} \mathrm{SO}_{4}$ was introduced to terminate the 

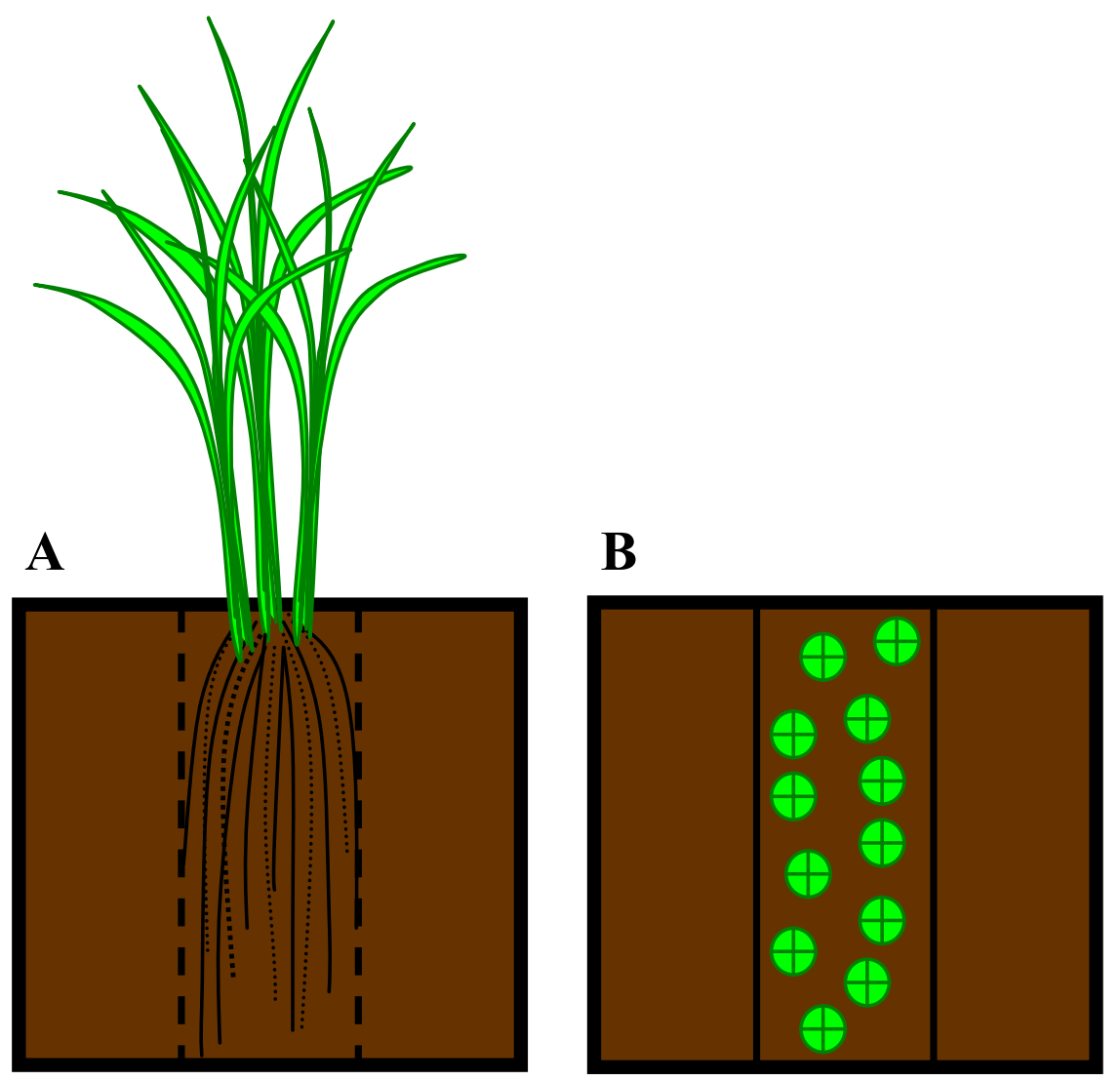

Fig. 1. Schematic diagram of ryegrass seedlings grown in soils contained in root box. (A) The sectional drawing of root box; (B), the horizontal plan of root box.

reaction. After centrifugation at $4000 \times \mathrm{g}$ for $5 \mathrm{~min}, 25 \mathrm{ml}$ of supernatant was obtained and titrated with $0.02 \mathrm{M} \mathrm{KMnO}_{4}$ until the color was blush. The soil catalase activities were expressed as $\mathrm{ml}$ $0.02 \mathrm{M} \mathrm{KMnO}_{4}(20 \mathrm{~min})^{-1} \mathrm{~g}^{-1}$ soil.

Soil polyphenol oxidase (E.C. 1.10.3.1) activity was measured according to the colorimetric method described by Zhan et al. (2010) and with minor modifications. The mixture of $2 \mathrm{~g}$ fresh soil and $10 \mathrm{ml} 1 \%$ pyrogallic acid (employed as substrate) was incubated at $30{ }^{\circ} \mathrm{C}$ for $2 \mathrm{~h}$ in the dark, and $4 \mathrm{ml}$ citric-phosphoric acid buffer ( $\mathrm{pH} 4.5$ ) was added to the mixture. The purpurigallin produced was extracted with ether, and then measured at $430 \mathrm{~nm}$. Soil polyphenol oxidase activities were expressed as mg purpurigallin $(2 \mathrm{~h})^{-1} \mathrm{~g}^{-1}$ soil.

\subsubsection{Pyrene extraction and analysis}

The procedure used to extract pyrene form the soils was a modification of those by Gao et al. (2005) and Kipopoulou et al. (1999). Two grams of freeze-dried soil sample was extracted for $1 \mathrm{~h}$ by ultrasonic treatment with two grams anhydrous sodium sulfate and $20 \mathrm{ml}$ dichloromethane in a glass centrifuge tube, followed by centrifugation at $4000 \times g$ for $5 \mathrm{~min}$ to separate the supernatant from the soil. Half of the supernatant $(10 \mathrm{ml})$ was collected in a $100 \mathrm{ml}$ round bottom flask and concentrated to about 2-3 ml using a rotary evaporator, dried with a gentle stream of nitrogen, solvated again with n-hexane and dried two times, the residue was subsequently dissolved in $1 \mathrm{ml}$ of $\mathrm{n}$-hexane and transferred carefully to sample vial and stored at $-20^{\circ} \mathrm{C}$ prior to GC analysis.

The quantification of pyrene was achieved by an Agilent 6820 gas chromatograph (GC) with a flame ionization detector (FID) equipped with a HP-5 MS capillary column $(0.32 \mathrm{~mm} \times 30 \mathrm{~m} \times 0.25 \mathrm{~mm})$. The oven-temperature program for pyrene analysis started at $100{ }^{\circ} \mathrm{C}$, held for $2 \mathrm{~min}$, then increased to
$250{ }^{\circ} \mathrm{C}$ at a rate of $25^{\circ} \mathrm{C} \mathrm{min}-1$, and held for $3 \mathrm{~min}$. The GC injection-port temperature and the detector temperature were both set at $280^{\circ} \mathrm{C}$. Nitrogen was used as carrier gas.

\subsection{Statistical analysis}

All data presented for the chemical and biological analyses of soils and plants are the means of four replicates, and they were subjected to the analysis of variance (ANOVA) in Statistical Package for Social Science (SPSS) (version 18.0 for Windows), the means were compared using least significant differences calculated at a significance level of $p=0.05$.

\section{Results and discussion}

\subsection{Isolation of pyrene-degrading bacteria and identification}

The pyrene-degrading bacteria, which isolated after enrichment and plate streaking, was named PW, it was ivory white, circular, and smooth surface in colony morphology and short rod in cell morphology (Fig. 2).

Phylogenetic analysis (Fig. 3) showed that PW was closely related to Ochrobactrum with a high homology beyond 99\%, according to this result, strain PW was assigned to Ochrobactrum sp.

The degradation ability was verified by adding PW into MSM with pyrene (100 $\mathrm{mg} \mathrm{l}^{-1}$ ) as sole carbon source, and incubated at $150 \mathrm{r} / \mathrm{min}, 30^{\circ} \mathrm{C}$ for 5 days. The same procedure was repeated several times, and after domestication, the degradation rate was increased from $62.3 \%$ to $92.7 \%$. 


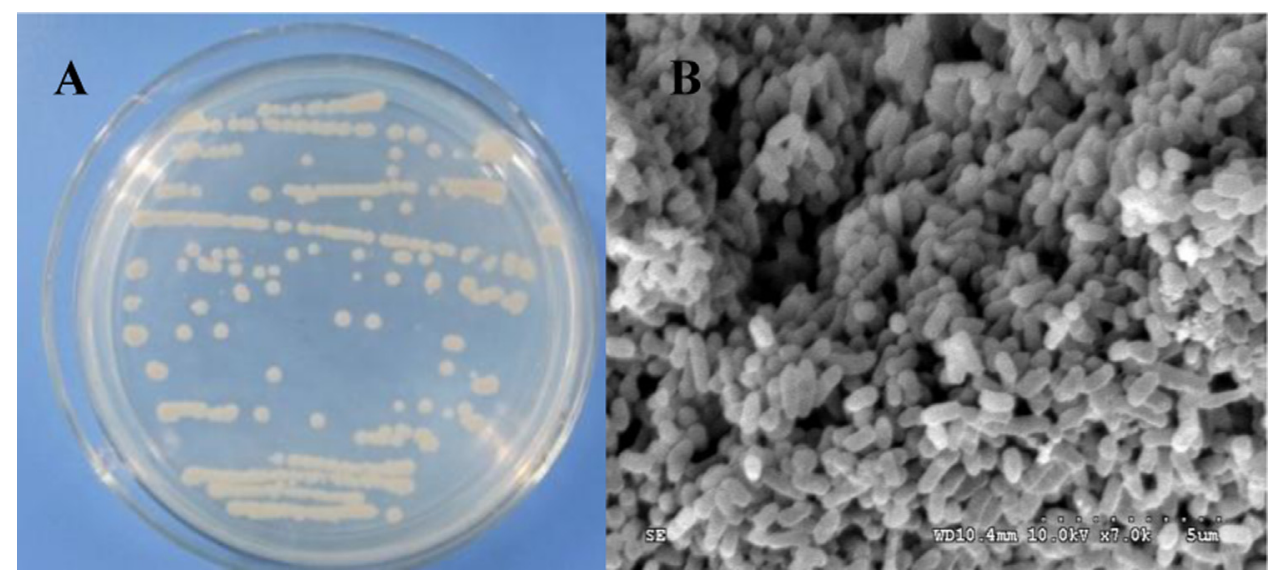

Fig. 2. The morphology in colony and cell of strain PW. (A) Colony of PW on LB plate; (B), the electronic microscope photograph of PW amplified by 7000 times.

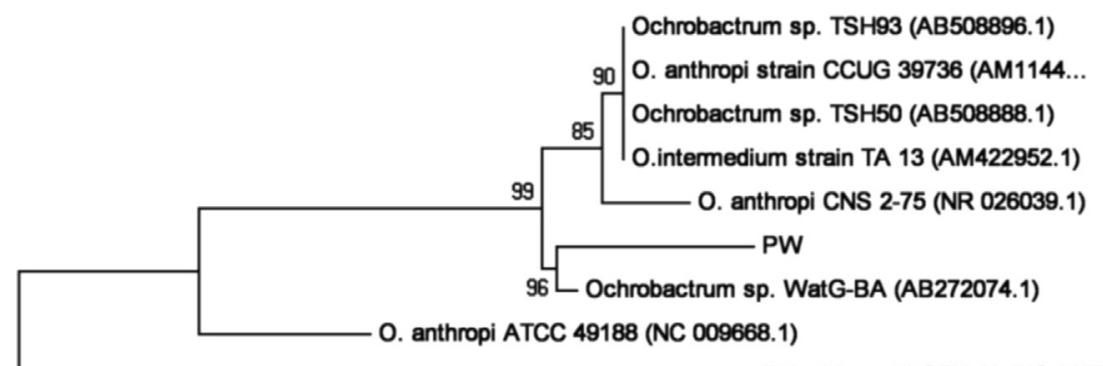

Rhizobium etli CFN 42 (NC 007761)

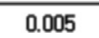

Fig. 3. The Phylogenetic tree of strain PW.

\subsection{Effect of bioaugmentation on mineralization of pyrene}

The residual concentrations of pyrene in rhizosphere soils and non-rhizosphere soils after 60 days planting were shown in Fig. 4. The concentrations of pyrene under planting of ryegrass plus PW inoculation treatment were significantly less than that of the treatment of planting of ryegrass $(p<0.05)$. However, the concentration of pyrene in rhizosphere soils showed no significant difference with those in non-rhizosphere soils $(p>0.05)$.

It is well known that PAHs-degrading bacteria play an important role in the mineralization of PAHs in contaminated soil (Atlas, 1995). So far, bacteria isolated from contaminated sites had been shown to be capable of degrading a range of PAHs (Cerniglia, 1992; Ye et al., 2014; Zeng et al., 2010). In our study, a high efficient pyrene-degrading bacterium PW belonging to genus Ochrobactrum was isolated after enrichment.

As previous reports, bioremediation of PAH-contaminated soil depend on the presence of degrading microorganisms which possess desired catabolic capabilities (Margesin and Schinner, 1997; Sun et al., 2012). Meanwhile, plant growth could accelerate the degradation rate at the same time (Sheng and Gong, 2006; Zhou et al., 2011). In the present study, Reintroduction of Ochrobactrum sp. PW into contaminated soil led to the significant removal $(p<0.05)$ of pyrene, which established its capability of degrading pyrene associated with soil particulates. It was shown that the pyrene degradation rate of treatments RP-r and RP-nr were $65.36 \%$ and $55.69 \%$ compared to R-nr treatment, nearly $60 \%$ and $50 \%$ higher than R-r treatment. The concentration of residual pyrene in rhizosphere soils of treatment inoculate with PW and planting of ryegrass (RP-r) was $818.7 \mathrm{ng} \mathrm{g}^{-1}$, yet it was $2109.6 \mathrm{ng} \mathrm{g}^{-1}$ of treatment R-r, more than 2.5 times higher of RP-r treatment. According to the criteria proposed by Maliszewska-

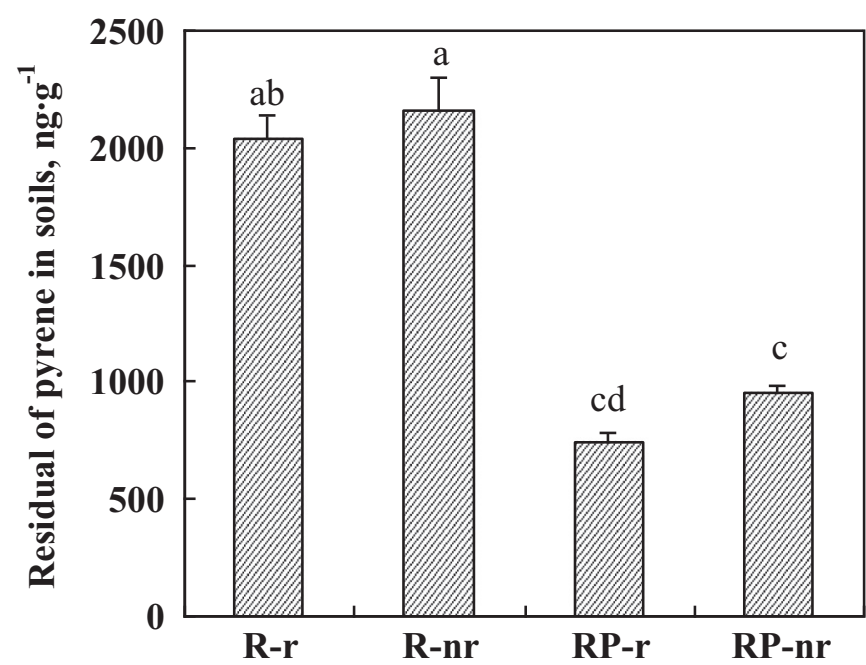

Fig. 4. The residual of pyrene in soils. R-r, rhizosphere soil of treatment planting of ryegrass; R-nr, non-rhizosphere soil of treatment planting of ryegrass; RP-r, rhizosphere soil of treatment planting of ryegrass and inoculate with PW; RP-nr, nonrhizosphere soil of treatment planting of ryegrass and inoculate with PW.

Kordybach (1996), there were four classes of soil contamination with PAHs: non-contaminated $\left(<200 \mathrm{ng} \mathrm{g}^{-1}\right)$, weakly contaminated (200-600 $\left.\mathrm{ng} \mathrm{g}^{-1}\right)$, contaminated (600-1000 $\mathrm{ng} \mathrm{g}^{-1}$ ) and heavily contaminated ( $>1000 \mathrm{ng} \mathrm{g}^{-1}$ ). Based on this criteria, soils in RP-r and RP-nr treatments were considered to be contaminated soil, soils only planted with ryegrass (R-r and R-nr) were still belong to the level of heavily contaminated. It was supposed that the inoculated microorganism may directly involve in the degradation process by secrete special degrading enzyme or 


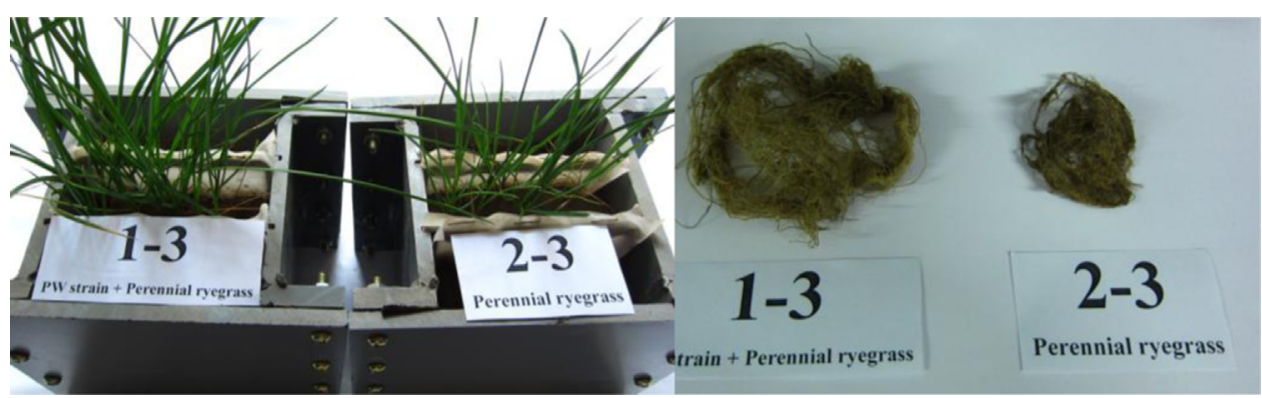

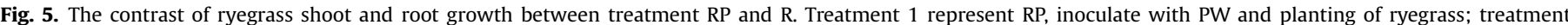
2 represent $R$, planting of ryegrass.

by producing biosurfactants for the solubilization of PAHs (Husain, 2008).

\subsection{Effect of bioaugmentation on microorganism communities and plant biomass}

It was shown that the inherent toxicity of pyrene in soils decreased which led to the vigorous growth of ryegrass no matter in shoot or root due to the activity of PW (Fig. 5). Plant biomass was measured at the end of the experiment to explore the influence of PW to the growth of ryegrass in pyrene contaminated soil. The shoot and root biomass of ryegrass on dry weight were shown in Fig. 6. The dry weight of RP treatment was approximately 2.8 and 3.3 times larger than only ryegrass treatment of root and shoot yields. It was indicated that root and shoot biomass of ryegrass of $\mathrm{RP}$ treatment were significantly higher than that of $\mathrm{R}$ treatment $(p<0.05)$. The results indicated that the interaction of $\mathrm{PW}, \mathrm{a}$ pyrene-degrading bacteria, and ryegrass could reduce the toxicity of PAHs contaminated soil to ryegrass.

After 60 days growth of ryegrass in the soil polluted with pyrene, the number of bacteria, actinobacteria and fungi were counted and results from microbial plate counts were shown in Table 1 . The number of these three microorganisms from highest to lowest was: RP-r $>$ R-r $>$ RP-nr $>$ R-nr. It was shown that under the treatment of planting ryegrass plus PW inoculation, the bacterial and actinomycic numbers in rhizosphere soils were more than two times larger than that of the non-rhizosphere soils

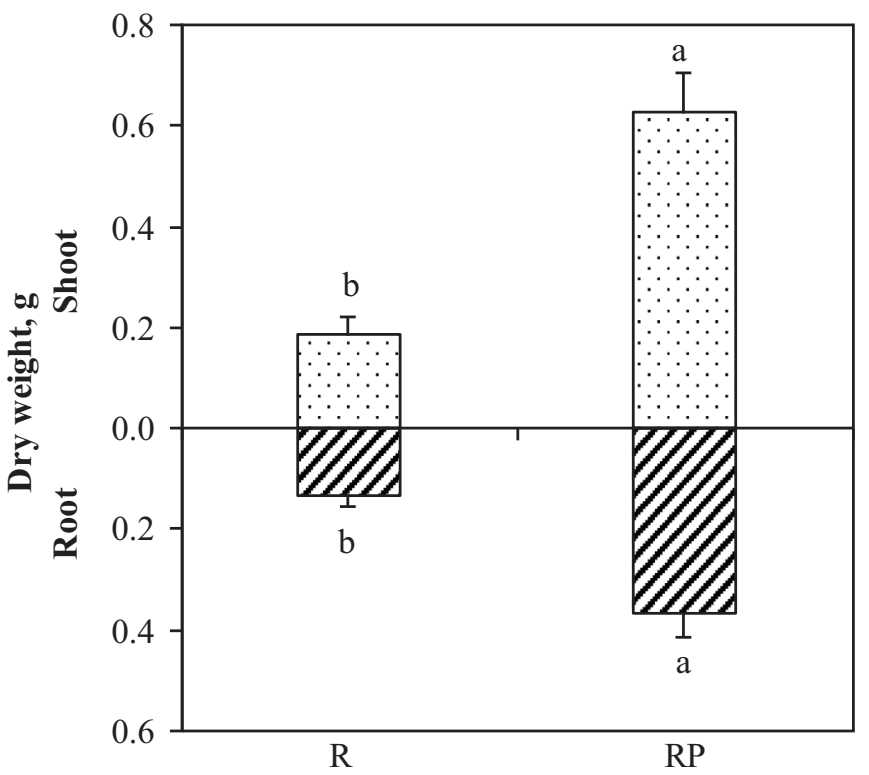

Fig. 6. Shoot and root biomass of ryegrass. R, planting of ryegrass; RP, planting of ryegrass and inoculate with PW.
Table1

The number of microbes in different treatments.

\begin{tabular}{llll}
\hline & Bacteria $\times 10^{5} \mathrm{CFU} \mathrm{g}^{-1}$ & Actinobacteria $\times 10^{4} \mathrm{CFU} \mathrm{g}^{-1}$ & Fungi CFU g \\
\hline $\mathrm{R}-\mathrm{r}$ & $0.980 \pm 0.081 \mathrm{ab}$ & $1.63 \pm 0.25 \mathrm{~b}$ & $19.2 \pm 1.6 \mathrm{a}$ \\
$\mathrm{R}-\mathrm{nr}$ & $0.822 \pm 0.063 \mathrm{BCE}$ & $0.679 \pm 0.121 \mathrm{~d}$ & $12.3 \pm 0.9 \mathrm{a}$ \\
$\mathrm{RP}-\mathrm{r}$ & $1.86 \pm 0.26 \mathrm{a}$ & $2.48 \pm 0.11 \mathrm{a}$ & $25.8 \pm 4.2 \mathrm{a}$ \\
$\mathrm{RP}-\mathrm{nr}$ & $0.857 \pm 0.071 \mathrm{~b}$ & $1.15 \pm 0.03 \mathrm{c}$ & $21.8 \pm 2.6 \mathrm{a}$ \\
\hline
\end{tabular}

$(p<0.05)$. However, without the PW inoculation no significant difference in bacterial numbers was observed between the rhizosphere and non-rhizosphere soils $(p>0.05)$. In the present research no significant difference in the fungal numbers was observed between the rhizosphere and non-rhizosphere soils of the two treatments $(p>0.05)$. These results indicated that inoculate with PW and planting of ryegrass both could enhance the growth of bacteria and actinobacteria in contaminated soils, and treatment RP-r possess the most remarkable effect.

Bioaugmentation had played an important role in bioremediation by promoting the growth of particular degrading microorganisms in contaminated soil (Cheema et al., 2009; Karamalidis et al., 2010; Lu et al., 2011; Teng et al., 2011). In our research a significant increase in counts of PAH-degrading bacteria and actinobacteria were observed in bioaugmented and ryegrass planting treatment (RP-r) compared with R-nr treatment, but no significant difference was observed between R-r and R-nr treatment of bacteria communities, which indicated that the number of microorganisms in rhizosphere soil could increase significantly after inoculation of Ochrobactrum sp. PW than non-rhizosphere soil. It was also reported by Sheng and Gong (2006) that the inoculated phenanthrene-degrading bacterial strain Pseudomonas sp. GF3 could colonize and develop in the rhizosphere soil of wheat after inoculation. Lu et al. (2011) also demonstrated that the copy number of PAHs dioxygenase gene nahAc increased by two orders of magnitude after the 30 days biodegradation tests. As for bacteria numbers, it was significantly higher in rhizosphere soil of RP treatment than non-rhizosphere soil, while there was no significant difference between rhizosphere and non-rhizosphere soils of $\mathrm{R}$ treatment, it was indicated that the inoculated microorganism could utilize pyrene as source carbon leading to rapidly reproduce in soil and this could enhance the growth of indigenous microbes, and with the rhizosphere effect of ryegrass, resulting in the significant increase of bacteria number in RP-r treatment.

As for the ryegrass, it was suggested that the ability of contaminated soil provided water and nutrients to plants might be limited due to the inherent toxicity of PAHs (Banks et al., 1996; Cheema et al., 2010). This may lead to a decline in biomass production of $\mathrm{R}$ treatment due to the absence of energy for ryegrass growing. Whereas the ryegrass growth could be promoted by inoculating with pyrene-degrading microorganism PW, due to its activity in soil, it could accelerate the degradation process, so as to reduce the toxicity of contaminated soil to plants (treatment RP). 
Sun et al. (2010) assumed that root-exudates-enhanced degradation was the predominant contribution for the decrease of soil phenanthrene and pyrene, but such stimulation was not significant in our study. In the presence of PW, the growth of bacteria, actinobacteria and ryegrass possess a synergistic effect. The roots are known to release root exudates, such as amino acids, sugars, enzymes and complex carbohydrates, providing carbon source and energy for the growth of rhizosphere microorganisms (Kaimi et al., 2007; Phillips et al., 2012; Sun et al., 2010). Parrish et al. (2005) reported that the $\mathrm{PAH}$-degrading microbial population in vegetated treatments were much higher than those in unvegetated controls after 12 months of plant growth, the same tendency was also found in our research, the number of bacteria and actinobacteria increased by the rhizosphere effect, meanwhile treatment inoculate with PW also possess a higher level of microbe in some extent. It was indicated that the interaction between microbes and plants in remediation of contaminated soil were complex and mutually beneficial to both organisms, this was also found by Tang et al. (2010).

\subsection{Effect of bioaugmentation on soil enzyme activities}

The catalase activities in different treatment were shown in Fig. 7(a). The PW inoculation and growth of ryegrass significantly $(p<0.05)$ increased catalase activities in soils of RP-r, RP-nr and $\mathrm{R}-\mathrm{r}$ treatments, when compared with R-nr soil, but no significant difference of catalase activities were observed between the three treatments: RP-r, RP-nr and R-r.

The polyphenol oxidase activity with $\mathrm{PW}$ inoculation was significantly $(\mathrm{p}<0.05)$ higher than that of the treatment without PW inoculation Fig. 7(b). However no significant difference was observed between rhizosphere soils and non-rhizosphere soils of treatment RP and R, which indicated that ryegrass growth had no significant influence on the activity of polyphenol oxidase.

It is commonly recognized that soil enzymes are very important to catalyze certain reactions in the decomposition of organics and the detoxification of xenobiotics. Soil enzyme activity is an indicator of microbial activity and some soil enzymes have a significant positive correlation with pollutant concentration (Zhang et al., 2009). It was shown that polyphenol oxidase activity

(a)

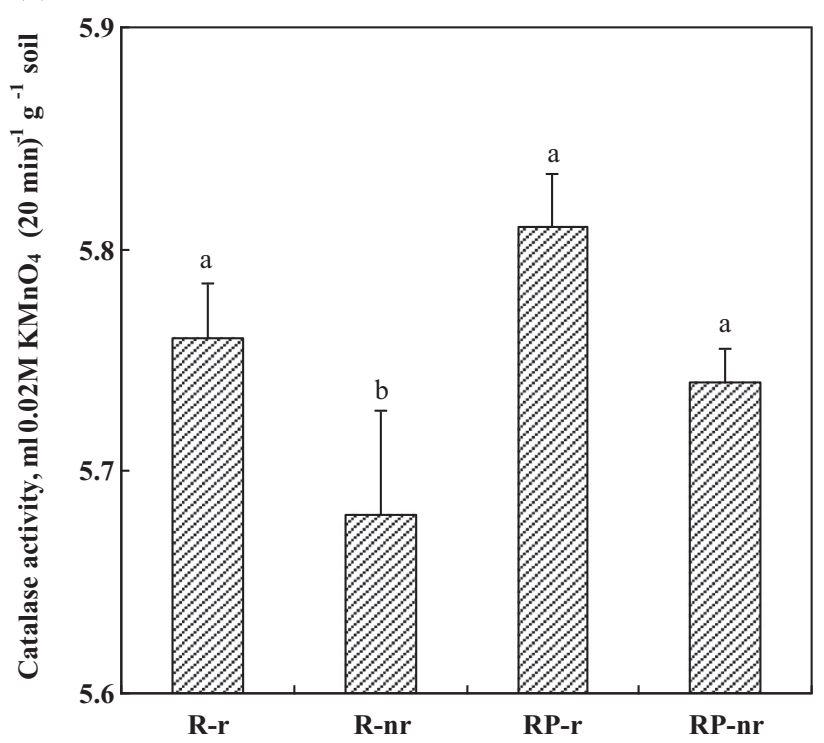

is affected by the inoculation of degrading microorganisms and catalase activity is affected by both the addition of microorganisms and plant growth.

Catalase is an oxidoreductase which is widely present in nature (Khan et al., 2007), it could enhance the oxidization of compounds by $\mathrm{H}_{2} \mathrm{O}_{2}$ (Ma et al., 2003) and kept cells away from damage caused by reactive oxygen species (Yao et al., 2006). Catalase activity in soils is considered an indicator of aerobic microbial activity and has been related to both the number of aerobic microorganisms and soil fertility (Garcia and Hernández, 1997). The enzymatic activities in RP-r, RP-nr and R-r treatments were all significantly higher than that of R-nr treatment, which was possibly attributed to the increase of organic material caused by the inoculation with PW and ryegrass plant.

Polyphenol oxidase is another important oxidoreductase in soil. In this study polyphenol oxidase activities were significantly $(\mathrm{p}<0.05)$ enhanced by pyrene-degrading bacteria PW, this was also found by Yu et al. (2011), but no significant difference was found between rhizosphere and non-rhizosphere soils of treatments R and RP, this trend matches well with the pyrene degradation data. It was indicated that PW inoculation was the main reason increased the activity of polyphenol oxidase. And the enhanced polyphenol oxidase activity in RP treatment may contribute to the increasing dissipation of pyrene as polyphenol oxidase can catalyze the degradation and transformation of aromatic compounds (Gramss et al., 1999; Liu et al., 2004). Thus, microbial degradation appears to be the most important approach during the remediation process and plant growth will in turn enhance the microbial growth of both native and introduced strains.

\section{Conclusion}

The present study indicates that pyrene-degrading bacteria PW can play a significant role in the mineralization of pyrene in soil and planting of ryegrass can enhance pyrene degradation in some extent. The PW-rhizobium symbiotic association can significantly increase ryegrass biomass, PAH-degrading bacterial counts and polyphenol oxidase activity in soil. The PW inoculation can enhance the degradation of pyrene in rhizosphere and non-

(b)

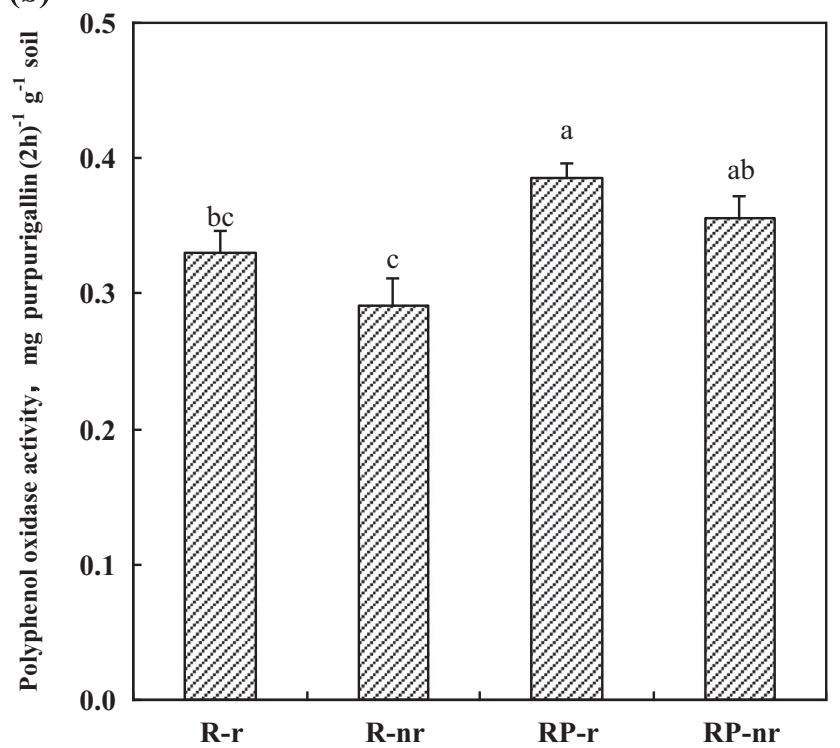

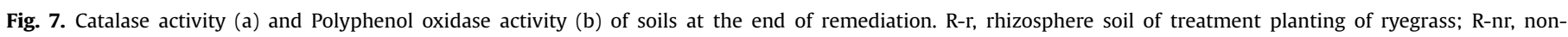

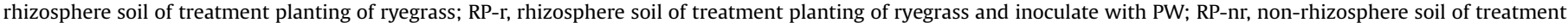
planting of ryegrass and inoculate with PW. 
rhizosphere soil by $65.36 \%$ and $55.69 \%$ compared to $\mathrm{R}$-nr treatment, which indicate that the bioaugmentation approach may be a prospect method for bioremediation of PAH-contaminated soil.

\section{Acknowledgment}

This project was supported by Beijing Natural Science Foundation (2162031); BUCT Fund for Disciplines Construction and Development (Project no. DCD XK1503).

\section{References}

Atlas, R.M., 1995. Bioremediation of petroleum pollutants. Int. Biodeterior. Biodegrad. $35,317-327$.

Baldrian, P. Wiesche, C.I.D., 2000. Influence of cadmium and mercury on activities of ligninolytic enzymes and degradation of polycyclic aromatic hydrocarbons by Pleurotus ostreatus in soil. Appl. Environ. Microbiol. 66, 2471-2478.

Banks, M., et al., 1996. Dissipation of polycyclic aromatic hydrocarbons in the rhizosphere. J. Environ. Qual. 25, 212-219.

Beg, M., et al., 2003. Distribution of petroleum hydrocarbon in sediment from coastal area receiving industrial effluents in Kuwait. Ecotoxicol. Environ. Saf. 54, 47-55.

Cerniglia, C.E., 1992. Biodegradation of polycyclic aromatic hydrocarbons. Biodegradation 3, 351-368.

Cheema, S.A., et al., 2009. Enhancement of phenanthrene and pyrene degradation in rhizosphere of tall fescue (Festuca arundinacea). J. Hazard. Mater. 166, 1226-1231.

Cheema, S.A., et al., 2010. Degradation of phenanthrene and pyrene in spiked soils by single and combined plants cultivation. J. Hazard. Mater. 177, 384-389.

Gao, Y., et al., 2005. Application of the partition-limited model for plant uptake of organic chemicals from soil and water. Sci. Total Environ. 336, 171-182.

Garcia, C., Hernández, T., 1997. Biological and biochemical indicators in derelict soils subject to erosion. Soil Biol. Biochem. 29, 171-177.

Gramss, G., et al., 1999. Oxidoreductase enzymes liberated by plant roots and their effects on soil humic material. Chemosphere 38, 1481-1494.

Husain, S., 2008. Effect of surfactants on pyrene degradation by Pseudomonas fluorescens 29L. World J. Microbiol. Biotechnol. 24, 2411-2419.

Kaimi, E., et al., 2007. Screening of twelve plant species for phytoremediation of petroleum hydrocarbon-contaminated soil. Plant Prod. Sci. 10, 211-218.

Kang, F., et al., 2010. Distribution of polycyclic aromatic hydrocarbons in subcellular root tissues of ryegrass (Lolium multiflorum Lam.). BMC Plant Biol. 10, 1-7.

Karamalidis, A., et al., 2010. Laboratory scale bioremediation of petroleum-contaminated soil by indigenous microorganisms and added Pseudomonas aeruginosa strain Spet. Bioresour. Technol. 101, 6545-6552.

Khan, S., et al., 2007. Soil enzymatic activities and microbial community structure with different application rates of Cd and Pb. J. Environ. Sci. 19, 834-840.

Kim, Y.H., et al., 2005. Effects of $\mathrm{pH}$ on the degradation of phenanthrene and pyrene by Mycobacterium vanbaalenii PYR-1. Appl. Microbiol. Biotechnol. 67, 275-285.

Kipopoulou, A., et al., 1999. Bioconcentration of polycyclic aromatic hydrocarbons in vegetables grown in an industrial area. Environ. Pollut. 106, 369-380.

Lee, S.H., et al., 2007. Degradation characteristics of waste lubricants under different nutrient conditions. J. Hazard. Mater. 143, 65-72.

Liu, S., et al., 2004. Degradation of benzo [a] pyrene in soil with arbuscular mycorrhizal alfalfa. Environ. Geochem. Health 26, 285-293.

Lu, X.Y., et al., 2011. Enhanced anoxic bioremediation of PAHs-contaminated sediment. Bioresour. Technol.

Ma, Y., et al., 2003. Microbial activity during composting of anthracene-contaminated soil. Chemosphere 52, 1505-1513.
Maliszewska-Kordybach, B., 1996. Polycyclic aromatic hydrocarbons in agricultural soils in Poland: preliminary proposals for criteria to evaluate the level of soil contamination. Appl. Geochem. 11, 121-127.

Margesin, R., Schinner, F., 1997. Efficiency of indigenous and inoculated coldadapted soil microorganisms for biodegradation of diesel oil in alpine soils. Appl. Environ. Microbiol. 63, 2660-2664.

Miya, R.K., Firestone, M.K., 2001. Enhanced phenanthrene biodegradation in soil by slender oat root exudates and root debris. J. Environ. Qual. 30, 1911-1918.

Moscoso, F., et al., 2012. Technoeconomic assessment of phenanthrene degradation by Pseudomonasstutzeri CECT 930 in a batch bioreactor. Bioresour. Technol. 104, 81-89.

Oleszczuk, P., 2009. Application of three methods used for the evaluation of polycyclic aromatic hydrocarbons (PAHs) bioaccessibility for sewage sludge composting. Bioresour. Technol. 100, 413-420.

Parrish, Z.D., et al., 2005. Effect of root death and decay on dissipation of polycyclic aromatic hydrocarbons in the rhizosphere of yellow sweet clover and tall fescue. J. Environ. Qual. 34, 207-216.

Phillips, L.A., et al., 2012. Plant root exudates impact the hydrocarbon degradation potential of a weathered-hydrocarbon contaminated soil. Appl. Soil Ecol. 52 56-64.

Ruuhola, T.M., 2000. Salicylates of intact Salix myrsinifolia plantlets do not undergo rapid metabolic turnover. Plant Physiol. 122, 895-905.

Samanta, S.K., et al., 2002. Polycyclic aromatic hydrocarbons: environmental pollution and bioremediation. Trends Biotechnol. 20, 243-248.

Sayara, T., et al., 2011. Bioremediation of PAHs-contaminated soil through composting: influence of bioaugmentation and biostimulation on contaminant biodegradation. Int. Biodeterior. Biodegrad.

Sheng, X., Gong, J., 2006. Increased degradation of phenanthrene in soil by Pseudomonas sp. GF3 in the presence of wheat. Soil Biol. Biochem. 38, 2587-2592.

Sun, T.R., et al., 2010. Roles of abiotic losses, microbes, plant roots, and root exudates on phytoremediation of PAHs in a barren soil. J. Hazard. Mater. 176, 919-925.

Sun, M., et al., 2012. Methyl- $\beta$-cyclodextrin enhanced biodegradation of polycyclic aromatic hydrocarbons and associated microbial activity in contaminated soil. J. Environ. Sci. 24, 926-933.

Tang, J., et al., 2010. Enhancement of soil petroleum remediation by using a combination of ryegrass (Lolium perenne) and different microorganisms. Soil Tillage Res. 110, 87-93.

Temple, K.L., Johnson, J.L., 1964. Some variables affecting the measurement of "catalase activity" in soil. Soil Sci. Soc. Am. J. 28, 207-209.

Teng, Y., et al., 2011. Influence of Rhizobium meliloti on phytoremediation of polycyclic aromatic hydrocarbons by alfalfa in an aged contaminated soil. J. Hazard. Mater. 186, 1271-1276.

Wilcke, W., 2007. Global patterns of polycyclic aromatic hydrocarbons (PAHs) in soil. Geoderma 141, 157-166.

Yao, X., et al., 2006. Influence of acetamiprid on soil enzymatic activities and respiration. Eur. J. Soil Biol. 42, 120-126.

Ye, J., et al., 2014. Pyrene removal and transformation by joint application of alfalfa and exogenous microorganisms and their influence on soil microbial community. Ecotoxicol. Environ. Saf. 110, 129-135.

Yu, X.Z., et al., 2011. Enhanced dissipation of PAHs from soil using mycorrhizal ryegrass and PAH-degrading bacteria. J. Hazard. Mater. 186, 1206-1217.

Zeng, J., et al., 2010. Isolation of polycyclic aromatic hydrocarbons (PAHs)-degrading Mycobacterium spp. and the degradation in soil. J. Hazard. Mater. 183, 718-723.

Zhan, X., et al., 2010. Interactive effect of dissolved organic matter and phenanthrene on soil enzymatic activities. J. Environ. Sci. 22, 607-614.

Zhang, Z., et al., 2009. Improvement of natural microbial remediation of petroleumpolluted soil using graminaceous plants. Water Sci. Technol. 59, 1025-1035.

Zhang, Y., et al., 2015. Polycyclic aromatic hydrocarbons in the food web of coasta wetlands: distribution, sources and potential toxicity. CLEAN-Soil Air Water 43 881-891.

Zhou, X., et al., 2011. Effects of intercropping cucumber with onion or garlic on soil enzyme activities, microbial communities and cucumber yield. Eur. J. Soil Biol. 